\title{
Processing of poly-L-lactide and poly(L-lactide-co-trimethylene carbonate) blends by fused filament fabrication and fused granulate fabrication using RepRap 3D printer
}

\author{
Jakub Marchewka ${ }^{1} \cdot$ Jadwiga Laska $^{1}$ \\ Received: 4 July 2019 / Accepted: 22 January 2020 / Published online: 29 January 2020 \\ (C) The Author(s) 2020
}

\begin{abstract}
The application of 3D printing by fused deposition modeling (FDM) and the low-cost RepRap 3D printer for the processing of poly-L-lactide (PLLA) and poly(L-lactide-co-trimethylene carbonate) (PLLATMC) blends was examined. Two blends with different mechanical properties were selected and the general scheme of their processing was proposed. For 80:20 PLLA:PLLATMC blend, fused filament fabrication (FFF) and the standard configuration of 3D printer were used, whereas for 30:70 PLLA:PLLATMC, the device was modified based on custom project for the application of fused granulate fabrication (FGF). The properties of the blends and their changes during the processing were analyzed by rheological measurements and size exclusion chromatography. Selected parameters of the printing process were optimized and their influence on the quality of the product was discussed. Both methods were used for the preparation of the scaffolds with different previously designed structures. The geometry of the scaffolds was characterized in relation to the parameters of the printing process, and base on this, the accuracy and precision of FFF and FGF methods were evaluated.
\end{abstract}

Keywords 3d printing $\cdot$ Fused deposition modeling $\cdot$ Polymer blends $\cdot$ Polylactide $\cdot$ Poly(trimethylene carbonate $) \cdot$ RepRap

\section{Introduction}

Natural and synthetic biodegradable polymers are one of the most important groups of the materials used in medicine [1, 2]. To adjust their properties to the specific requirements they are often applied as blends of an appropriate composition [2, $3]$. In tissue engineering, biodegradable polymers are used to prepare the scaffolds which support the regeneration of the damaged tissues. Their function is to mimic the properties and functions of the extracellular matrix. To ensure the positive results of treatment, the scaffolds should have a specific structure [4-7]. The shape and the dimensions have to be suited to the tissue defect. Microstructure including the porosity and pore size distribution need to provide a favorable environment for cell adhesion and proliferation. Mechanical

Jakub Marchewka

jmar@agh.edu.pl

1 Department of Biomaterials and Composites, Faculty of Materials Science and Ceramics, AGH University of Science and Technology, Mickiewicza 30, 30-059 Kraków, Poland properties of the scaffold have to ensure the stabilization of the defect site. Therefore, it is desirable to prepare the scaffolds with the structure tailored to the needs of a specific patient.

Using 3D printing methods the object is prepared by successive addition of the material to reproduce its virtual model [8-10]. This approach is different in comparison to the traditional techniques where the material is formed (molding, casting, forging, etc.) or removed (milling, drilling, turning, etc.). Stereolithography (SLA), selective laser sintering (SLS), and fused deposition modeling (FDM) were among the first developed and successfully applied methods of $3 \mathrm{D}$ printing. For the widespread use of FDM the RepRap project was established [11]. This allows the introduction on the market a range of low-cost solutions along with the devices and the software. Various constructions of printers were designed including Darwin and Mendel as one of the first and Prusa as one of the most popular. All of them based on thermal processing of the material whereas the differences were mainly among the used mechanical parts. 3D printing methods are used to process the polymers [12], ceramics [13], and metals [14] including the materials applied in medicine $[15,16]$. The products have a precisely defined and designed geometry including the shape, dimensions and porosity. The preparation of the 
scaffolds with potential application in tissue engineering is one of the possibilities $[17,18]$. In medicine, 3D printing methods could be also used for the preparation of the prostheses [19], pharmaceuticals [20, 21], anatomical models [22] or surgical devices [23].

Polylactide (PLA) is one of the most commonly applied biodegradable polymers. It is usually produced by polycondensation or ring-opening polymerization [24, 25]. PLA is widely used for the preparation of environmentally friendly materials [26] where its properties may be modified by various additives like soybean oil derivatives [27, 28]. It could be processed by injection molding, blow molding, or thermoforming [29], but in recent years, 3D printing methods are increasingly often used [30]. Semi-crystalline poly-Llactide (PLLA) and amorphous poly-D,L-lactide (PDLLA) are applied in medicine including the materials for orthopedics because of high mechanical properties of PLLA or the carriers for bioactive molecules due to the faster degradation of PDLLA [31]. PLLA scaffolds with the application in bone tissue engineering could be prepared by FDM [32], also with the additives as hydroxyapatite [33] or with collagen after further modification [34]. Other methods of the preparation include electrospinning for PLA scaffolds with hydroxyapatite and collagen [35] or porogen leaching for the scaffolds made of PLA blends with polyethylene glycol [36]. Amorphous poly(trimethylene carbonate) (PTMC) has only limited applications comparing with the other biodegradable polymers [37]. Because of its softness and low mechanical strength, the blends of PLA and PTMC or the copolymers of trimethylene carbonate with lactide or caprolactone are often made [38]. In medicine PTMC could be used for the preparation of the tubular structures for vascular tissue engineering [39], the carriers for bioactive molecules [40] or as the blends with PLLA for the preparation of the nerve guidance channels [41] or the materials for wound healing [42]. PTMC scaffolds with the application in cartilage tissue engineering could be prepared by SLA [43].

\section{Materials and methods}

\subsection{Polymers and polymer blends}

Semi-crystalline poly(L-lactide) (PLLA) in the form of white fibers and amorphous poly(L-lactide-co-trimethylene carbonate) $15 / 85$ (PLLATMC) in the form of yellow granulate were purchased from BioMatPol, Poland. The polymers are sold under the trade names of BIOCOP® PLLA Sn free and BIOCOP ${ }^{\circledR}$ PLLATMC $15 / 85$, respectively. This medicalgrade polymers with high purity and synthesized using nontoxic compounds could be used to prepare the materials with potential application in tissue engineering. Rigid PLLA and ductile PLLATMC were used to prepare a wide range of polymer blends with different mechanical properties. For this research, 80:20 and 30:70 (wt.\%) PLLA:PLLATMC blends were selected based on the preliminary tests as described previously [44].

\subsection{Materials for 3D printing}

Before further processing, PLLA and PLLATMC were dried at $80^{\circ} \mathrm{C}$ or $50{ }^{\circ} \mathrm{C}$, respectively, for $24 \mathrm{~h}$ under the reduced pressure of $10 \mathrm{mmHg}$. Both blends were prepared by melt mixing using Zamak EH-16H (Zamak Mercator, Poland) twin-screw extruder with nine heating zones. PLLA and PLLATMC in an appropriate mass ratio were mixed and fed into a hopper. The temperatures were optimized as $160^{\circ} \mathrm{C}$ for zone 1 and $175^{\circ} \mathrm{C}$ for zones $2-9$ or $130^{\circ} \mathrm{C}$ for zone $1,190^{\circ} \mathrm{C}$ for zones $2-6$ and $150^{\circ} \mathrm{C}$ for zones $7-9$ while the screw speed was set as $200 \mathrm{rpm}$ or $250 \mathrm{rpm}$ for the preparation of 80:20 PLLA:PLLATMC and 30:70 PLLA:PLLATMC blend, respectively. The blends were dried at $60{ }^{\circ} \mathrm{C}$ for $24 \mathrm{~h}$ under the reduced pressure of $10 \mathrm{mmHg}$ and granulated.

Both PLLA:PLLATMC blends were processed using 3D printing by fused deposition modeling (FDM). Depending on the form of the material (filament or granulate), the method was described as fused filament fabrication (FFF) or fused granulate fabrication (FGF). 80:20 PLLA:PLLATMC granulate was processed into the form of filament using Brabender 19/25 (Brabender, Germany) single screw extruder with four heating zones. The temperatures were optimized as $180^{\circ} \mathrm{C}$ for zone 1 and $200{ }^{\circ} \mathrm{C}$ for zones $2-4$ while the screw speed was set as $85 \mathrm{rpm}$. During the process, the product was spooled on a reel. 30:70 PLLA:PLLATMC granulate was not processed into the form of filament.

\subsection{D printing process}

RepRapPro Tricolour Mendel (RepRapPro, UK) based on the open-source RepRap project was applied as low-cost commercially available $3 \mathrm{D}$ printer with the open construction adjusted to process the thermoplastic polymers in the form of filament. The material is melted and deposited layer by layer on a heated surface. Mendel design applies a printer head with a heater and a nozzle moving in the $x$ - and $y$-axes and a bed moving in the $z$-axis which let to prepare the $3 \mathrm{D}$ object. The movements are provided by stepper motors and appropriately arranged pulleys and timing belts ( $x$ - and $y$-axes) or shaft couplings and threaded rods ( $z$-axis). Technical specification of the printer is described in Table 1.

For the processing of 80:20 PLLA:PLLATMC blend the device was used in the standard configuration (FFF method), while for 30:70 PLLA:PLLATMC blend, the construction was modified based on our project and adapted to process the material in the form of granulate (FGF method). In both configurations, the melted material was extruded from a $0.5-\mathrm{mm}$ 
Table 1 RepRapPro Tricolour Mendel specification according to the manufacturer.

\begin{tabular}{ll}
\hline Parameter & Value \\
\hline Overall size (width $\times$ length $\times$ height) $[\mathrm{mm}]$ & $500 \times 460 \times 410$ \\
Build volume $($ width $\times$ length $\times$ height) $[\mathrm{mm}]$ & $210 \times 190 \times 140$ \\
Nozzle diameter $[\mathrm{mm}]$ & 0.5 \\
Minimal layer height $[\mathrm{mm}]$ & 0.1 \\
Maximum heating bed temperature $\left[{ }^{\circ} \mathrm{C}\right]$ & 150 \\
Maximum nozzle temperature $\left[{ }^{\circ} \mathrm{C}\right]$ & 275
\end{tabular}

nozzle forming the product on a heating bed with the temperature of $20^{\circ} \mathrm{C}$ and covered with Kapton tape. The initial distance between the nozzle and the bed was set as $0.1 \mathrm{~mm}$. The nozzle temperature and the printing speed were optimized as $200{ }^{\circ} \mathrm{C}$ and $10 \mathrm{~mm} \mathrm{~s}^{-1}$ for 80:20 PLLA:PLLATMC blend and as $195^{\circ} \mathrm{C}$ and $3 \mathrm{~mm} \mathrm{~s}^{-1}$ for 30:70 PLLA:PLLATMC blend.

\subsection{Polymer processing characterization}

The changes of the average molar mass during the processing of 80:20 PLLA:PLLATMC and 30:70 PLLA:PLLATMC blends were analyzed by size exclusion chromatography. The tests were conducted for the initial physical mixtures of the polymers, for the materials prepared for 3D printing (filament or granulate) and for the blends after the processing. VE 1122 pump (Malvern Panalytical, UK), two PLgel 5- $\mu \mathrm{m}$ MIXED-C columns (Agilent Technologies, USA) and Shodex SE-61 refractive index detector (Showa Denko, Japan) were combined as the measuring system. For each test $100 \mu \mathrm{L}$ of $0.3 \%$ solution of the polymer in chloroform after filtration through $0.45 \mu \mathrm{m}$ filter was used as the sample. Two measurements were performed for each of them at the temperature of $35^{\circ} \mathrm{C}$ using chloroform as eluent at the flow rate of $1 \mathrm{~mL} \cdot \mathrm{min}^{-1}$ and polystyrene analytical standards.

The rheological properties of the blends were evaluated using Ares-G2 rheometer (TA Instruments, USA) equipped with a plate-plate measuring system. 80:20 PLLA:PLLATMC and 30:70 PLLA:PLLATMC blends as the samples in the shape of cylinders with a diameter of $25.00 \mathrm{~mm}$ and a height of $1.20 \mathrm{~mm}$ were analyzed at $200{ }^{\circ} \mathrm{C}$. Three types of the tests were performed including the flow ramp for increasing-decreasing shear rates between 10 and $100 \mathrm{~s}^{-1}$, the flow sweep for increasing-decreasing shear rates between $10^{-2} \mathrm{~s}^{-1}$ and $10^{4} \mathrm{~s}^{-1}$ and the frequency sweep for angular speeds between 1 and $600 \mathrm{rad} \mathrm{s}^{-1}$ and the amplitude of the stress of $1 \%$.

\subsection{Sample preparation and characterization}

3D models of the samples were designed using Blender software as porous scaffolds having the shape of cylinders with a diameter of $15.15 \mathrm{~mm}$ and a height of $1.20 \mathrm{~mm}$. The structure was built of the parallel bars with $0^{\circ} / 60^{\circ} / 120^{\circ}$ orientation between the layers (ABC arrangement, Fig. 1). The height of the layer and the thickness of the bar were equal to $0.3 \mathrm{~mm}$ so their cross section was circular. Four 3D models with the porosity of $65 \%, 55 \%, 45 \%$, and $35 \%(35 \%, 45 \%, 55 \%$, and $65 \%$ infill, respectively) were designed (Fig. 2) and saved as *.stl files. This kind of file describes a 3D object in the Cartesian coordinate system in the form of a surface mesh consisting of triangles. Slic3r software was used to convert *.stl files to *.gcode files with the application of appropriate parameters of the printing process. This type of file includes a set of instructions for the printer describing the material processing conditions and the material deposition in the 3D building volume. 3D printer was controlled with Poronterface software as a part of the Printrun package. Four scaffolds were prepared during one printing process giving a total of twenty samples of each type. The software based on the free GNU General Public License is typically applied with the RepRap 3D printers.

The quality of the scaffolds was evaluated based on the measurements of their diameter and height using a caliper and the measurements of their weight using an analytical weighing scale. Keyence VHX-900F (Keyence, Japan) optical microscope with the magnifications of $\times 20$ and $\times 100$ was also applied for a visual examination of the scaffolds.

\section{Results and discussion}

\subsection{Polymers and polymer blends}

PLLA and PLLATMC were chosen for the preparation of the materials for $3 \mathrm{D}$ printing based on two main criteria including an appropriate mechanical and thermal properties, as described previously [41]. For PLLA and PLLATMC ultimate tensile strength was measured as $47.12 \pm 0.98 \mathrm{MPa}$ and 0.31 $\pm 0.02 \mathrm{MPa}$, whereas Young modulus as $2485 \pm 153 \mathrm{MPa}$ and $0.64 \pm 0.14 \mathrm{MPa}$, respectively. With significantly different mechanical properties a wide range of the blends could be prepared. Based on DSC analysis PLLA as the semicrystalline polymer demonstrated the glass transition at $45.56{ }^{\circ} \mathrm{C}$ and the melting point at $177.24{ }^{\circ} \mathrm{C}$, while PLLATMC as the amorphous polymer revealed only the glass

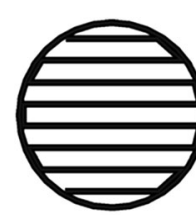

layer $\mathrm{A}$

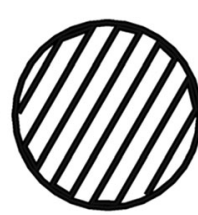

layer B

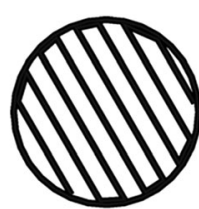

layer $\mathrm{C}$

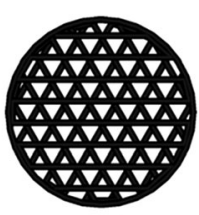

$\mathrm{ABC}$ arrangement
Fig. 1 The geometry of designed 3D models of the scaffolds 
Fig. 2 The models of the scaffolds with different porosities
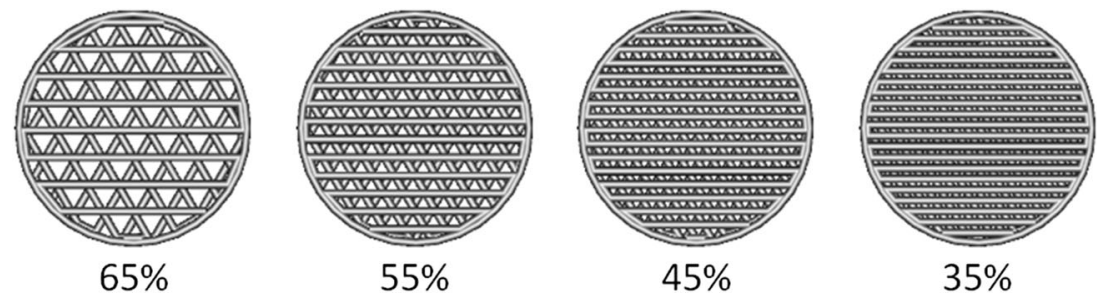

transition at $-7.38^{\circ} \mathrm{C}$. Therefore, both of them as the thermoplastic materials could be processed using $3 \mathrm{D}$ printing by FDM. The third criterion was additionally assumed taking into consideration the potential application of the product. For tissue engineering, both biodegradable polymers have to be commercially available with medical-grade quality.

80:20 PLLA:PLLATMC and 30:70 PLLA:PLLATMC (wt.\%) blends were selected and analyzed, as described previously [41]. The blends have significantly different mechanical properties, so they could be assumed as the two materials applied in tissue engineering of two various types of tissues (for example bone and cartilage). For 80:20 PLLA:PLLATMC and 30:70 PLLA:PLLATMC blends, ultimate tensile strength was measured as $30.49 \pm 3.06 \mathrm{MPa}$ and $0.34 \pm 0.02 \mathrm{MPa}$, whereas Young's modulus as $1786 \pm$ $81 \mathrm{MPa}$ and $2.95 \pm 0.36 \mathrm{MPa}$, respectively. PLLA after the addition of a relatively small amount of PLLATMC (as is the case of 80:20 PLLA:PLLATMC blend) retains high mechanical properties, but becomes more flexible which is desired for the materials applied in 3D printing. In the typical form of filament, it should not be too brittle to facilitate the manipulation and application for the standard 3D printers. Similarly, PLLATMC with the addition of PLLA (as for 30:70 PLLA:PLLATMC blend) is more rigid, but still has low mechanical properties. The thermal properties were similar for both blends. For 80:20 PLLA:PLLATMC two glass transitions were observed at $-4.13^{\circ} \mathrm{C}$ and $49.49{ }^{\circ} \mathrm{C}$ and the melting point at $179.90^{\circ} \mathrm{C}$, while for 30:70 PLLA:PLLATMC two glass transitions at $-10.73{ }^{\circ} \mathrm{C}$ and $49.36^{\circ} \mathrm{C}$ and the melting point at $176.68^{\circ} \mathrm{C}$. These temperatures were used as the reference values during the optimization of the $3 \mathrm{D}$ printing process parameters.

\subsection{Materials for 3D printing}

According to ISO/ASTM 52900:2015 standard, the material extrusion is one of the seven approaches to the processing of materials using $3 \mathrm{D}$ printing. In this technique, the material is melted, pushed through a nozzle and deposited layer by layer to reproduce the previously designed model of the object. FDM is the general name for this type of 3D printing, but depends on the form of material and the type of the extruder two basic and different method could be distinguished. The most widely used FDM method is FFF where the material in the form of filament is transferred by the gears. Its popularity based on relative simplicity and broad availability of the lowcost solutions in the market. Preparation of high-quality filament with a specific and constant diameter is the basic requirement, so only certain materials with the appropriate mechanical properties could be processed by FFF. The filament should not be too brittle or too flexible because either it could break in the extruder or it could block the gears. As an alternative, the second FDM method could be used where the material is applied directly in the form of granulate. In this work, it was named as FGF. In comparison with FFF, this method is not so limited by the type of material, but the construction of 3D printer is considerably more sophisticated to ensure the complete melting, homogeneous flow, and uniform deposition. For this reason, despite FGF versatility, the lowcost solutions are not available on the market.

The general scheme of PLLA:PLLATMC scaffold preparation was determined taking into consideration the properties of the polymers and the capabilities of FFF and FGF methods (Fig. 3). At first, both PLLA:PLLATMC blends were prepared in the form adequate for 3D printing. Applied parameters including the temperatures of the extruder heating zones and the screw speeds were optimized based on our experience in the area of polymer processing. The form of filament was desired because of its simple application using the standard low-cost 3D printer. For 80:20 PLLA:PLLATMC blend with high mechanical properties the procedure involves two steps with granulate as the intermediate. High-quality filament was produced with a diameter of $1.71 \pm 0.04 \mathrm{~mm}$ (based on 100 measurements along the whole length using caliper) where $1.75 \pm$ $0.05 \mathrm{~mm}$ is generally accepted as the standard for commercially available materials. Initial test for 30:70 PLLA:PLLATMC blend showed that because of its significantly lower mechanical properties, the filament with appropriate quality could not be prepared. Therefore, for this blend, the form of granulate was applied for 3D printer. For these reasons, the general scheme of PLLA:PLLATMC scaffolds preparation consists of three steps in case of $80: 20$ PLLA:PLLATMC blend and two steps for 30:70 PLLA:PLLATMC blend.

\subsection{D printing process}

In this work, the RepRap 3D printer was applied as the example of low-cost commercially available device. Based on the open-source project and build mainly from cheap standard 
Fig. 3 The general scheme of PLLA:PLLATMC scaffold preparation

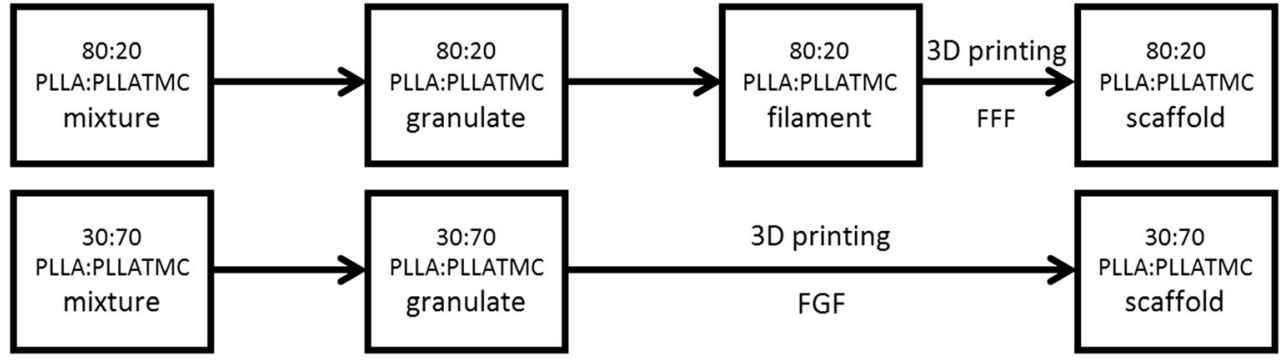

parts it gives the possibility to modify the construction. This could be very useful when non-standard materials are processed by $3 \mathrm{D}$ printing.

For 80:20 PLLA:PLLATMC blend, the printer was applied in standard configuration using the material in the form of filament. However, for 30:70 PLLA:PLLATMC blend, it was necessary to adapt the device and install an appropriate module to process the granulate (Fig. 4). For the purpose of the project these preliminary assumptions were formulated:

- New module should guarantee the complete and homogeneous melting of the granulate with a precise control of the temperature.

- Modified device should ensure the deposition of a certain amount of the melted material.

- New module should be adjusted to the standard framework of 3D printer.

- New module should have a limited mass to avoid an excessive load on the moving parts.

- Standard parts including these from the RepRap project should be used where it is possible.

- The module should be easy to assembly and disassembly depends on the adaptation of the printer for FGF or FFF method.

Based on them the custom modification was introduced and tested.
New module was installed on a frame for $x$-axis in the space of a standard 3D printer head used for the processing of filament. The main parts (Fig. 5) include NEMA 17 stepper motor (a), shaft coupling (b), $8 \mathrm{~mm}$ diameter screw (c), $40 \mathrm{~W}$ ceramic heater (d), $100 \mathrm{k}$ thermistor (e), aluminum heating block (f), $0.4 \mathrm{~mm} \mathrm{noz-}$ zle (g), insulation (h), and two cooling turbine fans (i). The screw and the heating block were prepared especially for the module whereas all other parts were standard and commonly used in 3D printers and similar devices. The stepper motor, ceramic heater and thermistor were the same type as these in the standard configuration of the $3 \mathrm{D}$ printer so the original wiring and plugs could be used. Vertically aligned screw driven by the stepper motor was applied to extrude the material through the heating block and the nozzle.

The optimization of the 3D printing process is performed to ensure the highest quality of the prepared product. For this method the quality could be characterized according to the following terms:

- Resolution - a size of the smallest elements which could be obtained during the process.

- Accuracy - consistency between the obtained and the designed geometry of the product.

- Precision-repeatability of the product geometry during the same subsequent processes.

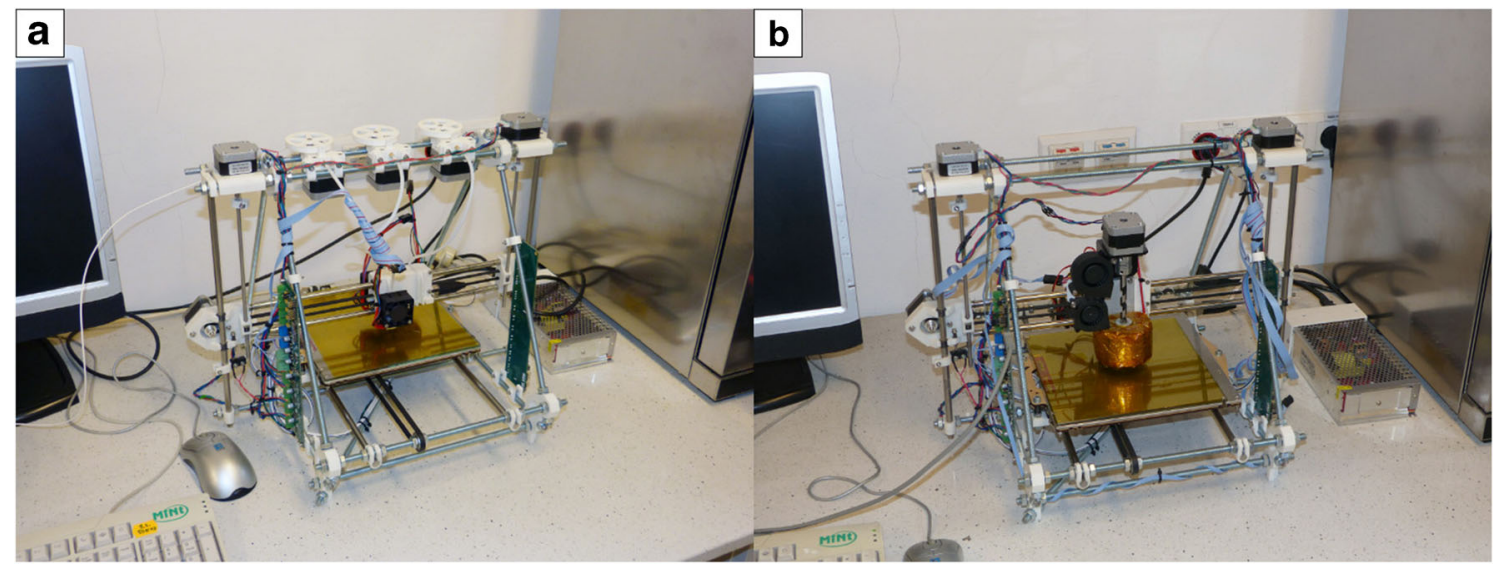

Fig. 4 3D printer in the standard (a) and modified (b) configuration adapted for the processing of filament or granulate, respectively 
Fig. 5 New module applied for the processing of material in the form of granulate (letters indicate the parts referred in the text)

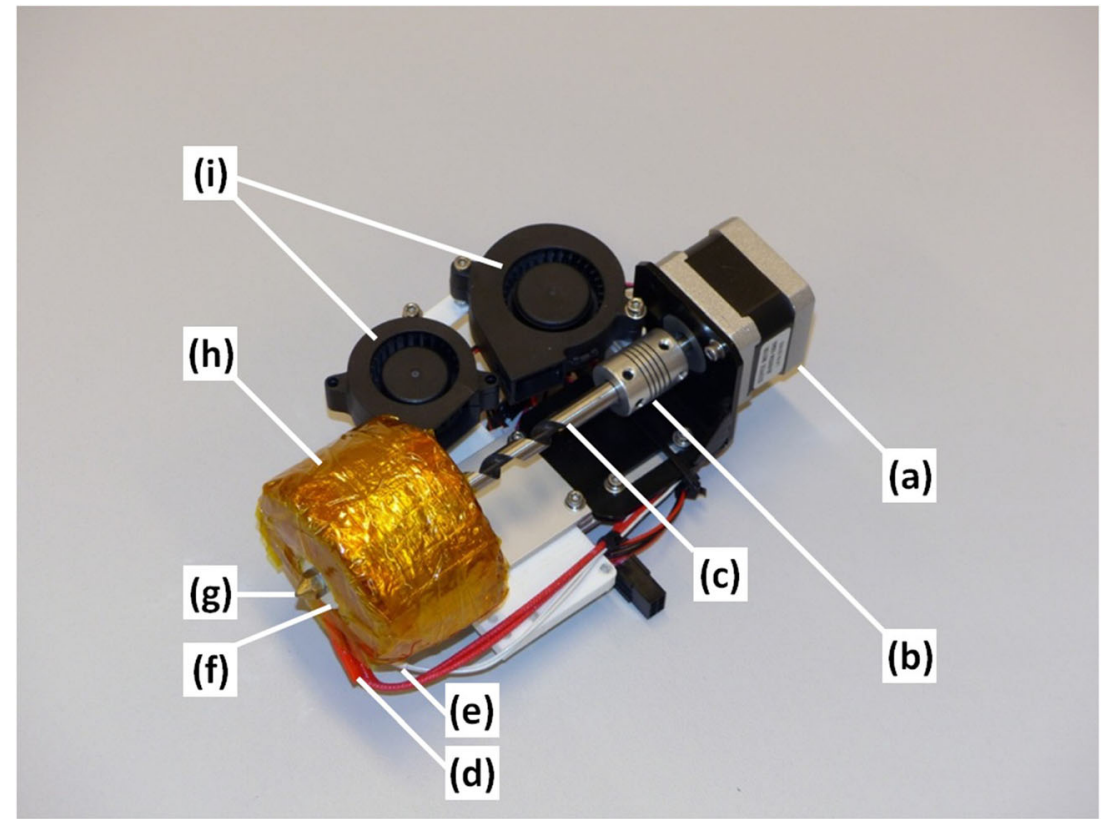

- Tolerance-acceptable difference between the obtained and designed geometry of the product with regard to specific requirements.

The conditions and parameters of the printing process for both PLLA:PLLATMC blends were optimized for the preparation of the scaffolds with potential application in tissue engineering. Therefore, the test was performed for various porous structures with dimensions of the order of millimeters. There are few factors which have to be considered during the optimization to ensure the correct 3D printing process and high quality of the product.

An appropriate and permanent adhesion of the product to the heating bed during its preparation is the basic problem. For this, three factors should be analyzed including the type of the material covering the heating bed, the temperature of the bed and the initial distance between the nozzle and the bed. Specific materials are used on the glass surface of the bed to improve the adhesion of the product. Kapton tape was applied because of its resistance for heat and chemicals, but other commercially available materials like foils or sprays are also in widespread use. Heating of the bed during the 3D printing process should keep the product at the temperatures above the glass transition of the material when the mobility of the polymer chains is increased. This ensures better adhesion between the product and the bed and also between subsequent deposited layers, but at the same time, the thermal deformations of the product could arise. To avoid this undesirable effect, the temperature of the heating bed was kept at $20{ }^{\circ} \mathrm{C}$. The initial distance between the nozzle and the bed should be set at the distance smaller than the height of the first layer. This could also introduce some deformations of the geometry, but increased spreading of the material on the bed significantly improves the adhesion. Therefore, this distance was set as $0.1 \mathrm{~mm}$.

The nozzle temperature and the printing speed are the two critical factors which substantially influence the quality of the product prepared during the $3 \mathrm{D}$ printing process. Both parameters were optimized to provide the uniform and homogeneous flow of the melted material and to reduce the die swell. This gives the proper reproduction of the designed geometry and the high resolution which are crucial for the preparation of the scaffolds. Initially after melting the polymer chains are entangled and randomly oriented. In the nozzle, they begin to deform and order parallel to the direction of the flow. After they leave it, the previous more spherical conformations are rearranged. The rate of this stress relaxation is increased at higher temperatures, and consequently, the die swell is
Table 2 The changes in the average molar mass during the processing of blends

\begin{tabular}{|c|c|c|c|c|}
\hline & \multicolumn{2}{|c|}{ 80:20 PLLA:PLLATMC } & \multicolumn{2}{|c|}{ 30:70 PLLA:PLLATMC } \\
\hline & $\mathrm{M}_{\mathrm{n}}\left[\mathrm{kg} \cdot \mathrm{mol}^{-1}\right]$ & $\Delta \mathrm{M}_{\mathrm{n}}[\%]$ & $\mathrm{M}_{\mathrm{n}}\left[\mathrm{kg} \cdot \mathrm{mol}^{-1}\right]$ & $\Delta \mathrm{M}_{\mathrm{n}}[\%]$ \\
\hline Initial mixture of the polymers & $92.977 \pm 8.186$ & 0 & $63.377 \pm 5.122$ & 0 \\
\hline Material applied for 3D printer & $61.215 \pm 1.763$ & -34.2 & $52.241 \pm 0.716$ & -17.6 \\
\hline Material after 3D printing process & $58.690 \pm 1.413$ & -36.9 & $39.186 \pm 0.635$ & -38.2 \\
\hline
\end{tabular}



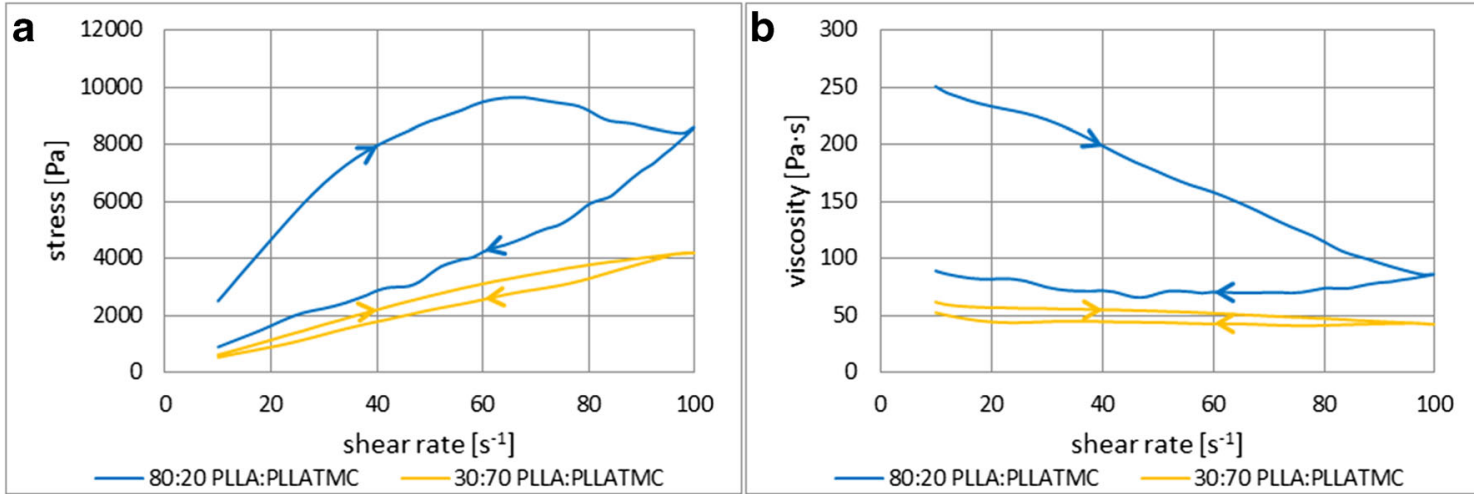

Fig. 6 The dependence of the stress (a) and the viscosity (b) on the increasing-decreasing shear rates between 10 and 100 $\mathrm{s}^{-1}$ (flow ramp test) for 80:20 PLLA:PLLATMC and 30:70 PLLA:PLLATMC blends at $200{ }^{\circ} \mathrm{C}$

reduced. However, at the same time, the viscosity decreases resulting in the deformation of the deposited material. At higher temperatures, thermal degradation is also increased which significantly affect the properties of the material. After taking into account these effects the nozzle temperature was optimized as $200{ }^{\circ} \mathrm{C}$ for 80:20 PLLA:PLLATMC blend and as $195{ }^{\circ} \mathrm{C}$ for $30: 70$ PLLA:PLLATMC blend. The test was performed at $5{ }^{\circ} \mathrm{C}$ intervals and the resolution for prepared samples was evaluated by optical microscopy. The printing speed is defined as a distance traveled by the nozzle at a given time during the printing. Shorter duration of the process is desired, but at higher printing speeds the uniform flow of the melted material and its deposition are disturbed. The time between the preparation of the subsequent layers is also insufficient for the cooling and consequently the significant deformations could occur. On the contrary, at lower printing speeds the contact between the hot nozzle and the previously deposited material is long. This could also result in the deformations and thermal degradation. Based on these considerations and the tests, the printing speed was optimized as $10 \mathrm{~mm} \mathrm{~s}^{-1}$ for 80:20 PLLA:PLLATMC blend and $3 \mathrm{~mm} \mathrm{~s}^{-1}$ for 30:70 PLLA:PLLATMC blend. The lower value for the second material used in the form of granulate was necessary to ensure its complete melting and homogeneous flow with the application of the custom modification of the printer.

\subsection{Polymer processing characterization}

Thermal processing of the polymers always results in the reduction of their molar mass. This undesirable effect is a consequence of the breakage in the chemical bonds of polymer chains and leads to the changes in the material properties. For polyesters depolymerization and intramolecular or intermolecular transesterification are assumed to be the dominant mechanisms. They are more intense in the presence of catalysts remnants, monomers and other impurities. Therefore, for the applied medical-grade polymers, the occurrence of these mechanisms should be limited. The changes in the average molar mass during the processing of blends were analyzed by size exclusion chromatography. Three tests were performed for each blend at the different stages of their processing.

The first test was conducted for the initial physical mixture of the polymers in a specific weight ratio, the second for the blend in the form applied for 3D printer (filament or granulate), and the last for the blend after the $3 \mathrm{D}$ printing process.
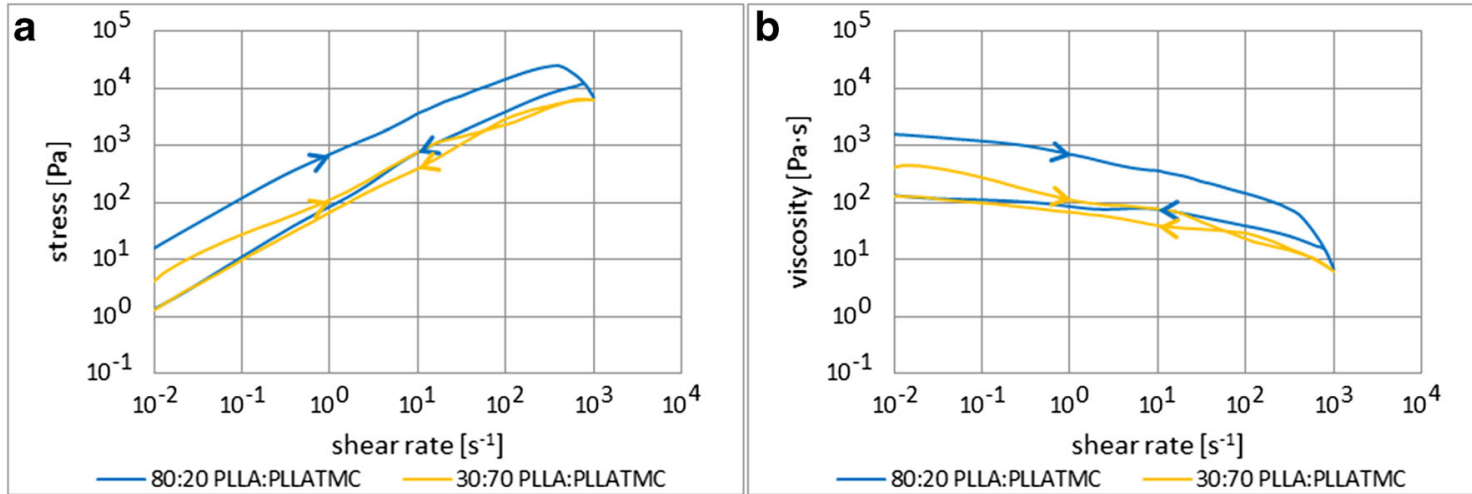

Fig. 7 The dependence of the stress (a) and the viscosity (b) on the increasing-decreasing shear rates between $10^{-2} \mathrm{~s}^{-1}$ and $10^{4} \mathrm{~s}^{-1}$ (flow sweep test) for 80:20 PLLA:PLLATMC and 30:70 PLLA:PLLATMC blends at $200^{\circ} \mathrm{C}$ 

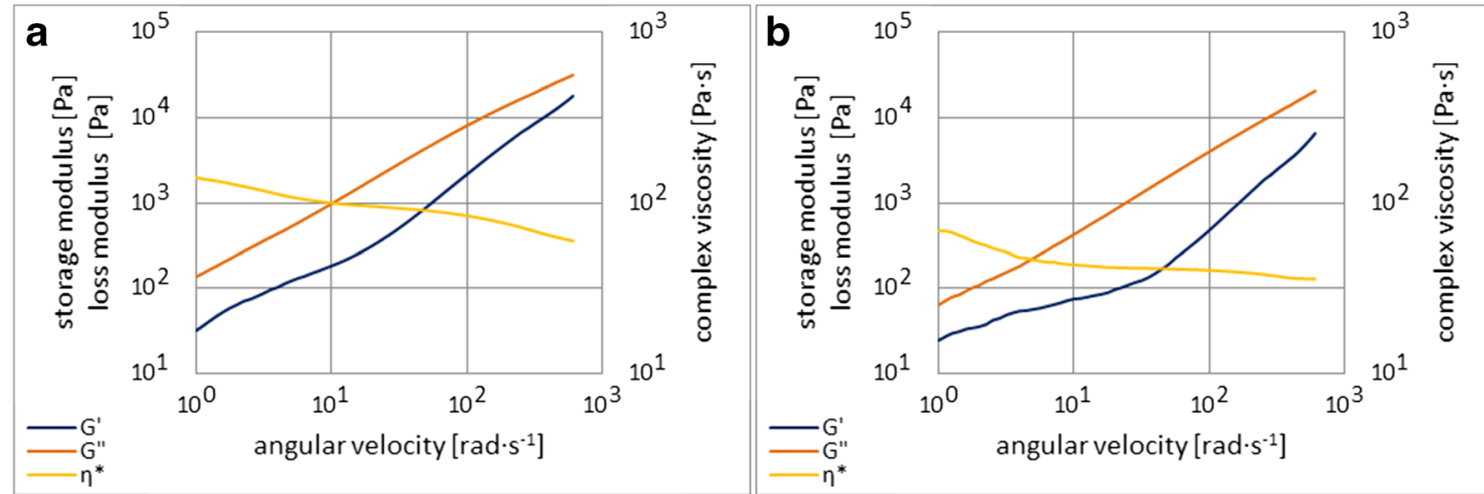

Fig. 8 The dependence of the storage modulus $\left(G^{\prime}\right)$, the loss modulus $\left(G^{\prime \prime}\right)$ and the complex viscosity $\left(\eta^{*}\right)$ on the angular speeds between $1 \mathrm{rad} \cdot \mathrm{s}^{-1}$ and $600 \mathrm{rad} \cdot \mathrm{s}^{-1}$ (frequency sweep test) for 80:20 PLLA:PLLATMC (a) and 30:70 PLLA:PLLATMC (b) blends at $200{ }^{\circ} \mathrm{C}$

The results are presented in Table 2. In the first stage of the process, the decrease in the average molar mass calculated in the reference to the initial mixtures of the polymers was $34.2 \%$ for $80: 20$ PLLA:PLLATMC and $17.6 \%$ for $30: 70$ PLLA:PLLATMC. The higher value for the first blend is a result of the longer thermal processing including a two-step preparation of the filament in comparison with a one-step preparation of the granulate for the second blend.

However, after the $3 \mathrm{D}$ printing process, the decrease in the average molar mass was calculated as $36.9 \%$ for $80: 20$ PLLA:PLLATMC and $38.2 \%$ for 30:70 PLLA:PLLATMC, so the results are similar for both blends. Contrary to the first stage, the thermal processing of 80:20 PLLA:PLLATMC blend with the application of FFF method is shorter as a result of the higher printing speed $\left(10 \mathrm{~mm} \cdot \mathrm{s}^{-1}\right)$. For $30: 70$ PLLA:PLLATMC blend, the overall time of the contact with high temperature is significantly longer not only as a consequence of lower printing speed $\left(3 \mathrm{~mm} \cdot \mathrm{s}^{-1}\right)$ but also because of the application of the bigger heating element used to ensure complete melting of the material in the modified construction of the printer.

The parameters of thermal processing of the polymers are also related to their rheological properties. Therefore, they were characterized for both blends at the same temperature of $200{ }^{\circ} \mathrm{C}$. During the measurements, the dependence of the stress and the viscosity on the increasing-decreasing shear rates was analyzed. The shear rates were applied in the range from 10 to $100 \mathrm{~s}^{-1}$ for the flow ramp test (Fig. 6) and from $10^{-2} \mathrm{~s}^{-1}$ to $10^{4} \mathrm{~s}^{-1}$ for the flow sweep test (Fig. 7). For the first one, the values are typical for the processing of polymers by FDM, whereas for the second one, they are corresponding to the dynamic conditions of the process.

For both blends, the stress-shear rate and the viscosityshear rate curves form the hysteresis loops and thixotropy is observed. Therefore, the analyzed properties depend on the time scale of the measurements. For melted polymers with the increasing shear rates, the spatial arrangement of the polymer chains is damaged. Then, with the decreasing shear rates, this structure is reconstructed, but this process takes a longer time. As a consequence, the changes in the stress and the viscosity are not the same for the increasing and decreasing shear rates.

In the measuring conditions, the viscosity decrease with the shear rate, so both blends act as non-Newtonian fluids. For melted polymers, this parameter changes with their flow rate. Initially, the polymer chains in the lowest energy conformations are entangled and randomly oriented. The flow resistance and consequently the viscosity are constant. Then, with the increasing flow rate, they start to deform and align in the direction of the flow. Their interactions get lower and as a
Table 3 The summary of the geometry parameters for $80: 20$ PLLA:PLLATMC and 30:70 PLLA:PLLATMC scaffolds prepared by FFF and FGF methods, respectively

\begin{tabular}{lllll}
\hline Sample & $\begin{array}{l}\text { Obtained height } \\
{[\mathrm{mm}]}\end{array}$ & $\begin{array}{l}\text { Obtained diameter } \\
{[\mathrm{mm}]}\end{array}$ & $\begin{array}{l}\text { Obtained porosity } \\
{[\%]}\end{array}$ & $\begin{array}{l}\text { Designed porosity } \\
{[\%]}\end{array}$ \\
\hline S1 & $1.05 \pm 0.02$ & $15.15 \pm 0.02$ & $64.9 \pm 0.7$ & 65 \\
S2 & $1.00 \pm 0.01$ & $15.11 \pm 0.02$ & $54.7 \pm 0.6$ & 55 \\
S3 & $0.98 \pm 0.01$ & $15.09 \pm 0.03$ & $44.7 \pm 0.6$ & 45 \\
S4 & $0.97 \pm 0.01$ & $15.06 \pm 0.02$ & $34.5 \pm 0.7$ & 35 \\
S5 & $0.90 \pm 0.02$ & $14.89 \pm 0.05$ & $66.0 \pm 1.6$ & 65 \\
S6 & $0.95 \pm 0.02$ & $14.80 \pm 0.05$ & $53.8 \pm 3.0$ & 55 \\
S7 & $0.91 \pm 0.01$ & $14.86 \pm 0.06$ & $44.3 \pm 3.8$ & 45 \\
S8 & $0.93 \pm 0.02$ & $14.85 \pm 0.06$ & $34.6 \pm 3.2$ & 35 \\
\hline
\end{tabular}




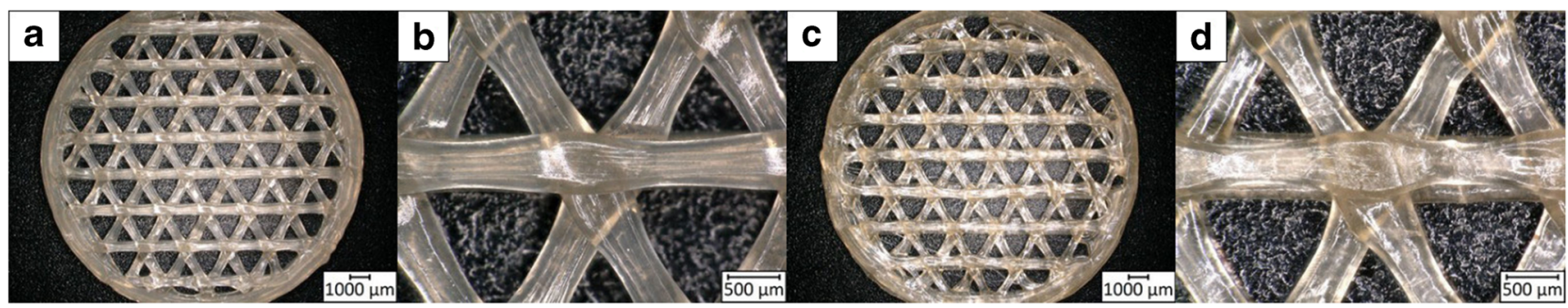

Fig. 9 Microscopic images of 80:20 PLLA:PLLATMC (a and b, sample S1) and 30:70 PLLA:PLLATMC (c and d, sample S5) scaffolds with 65\% porosity at the magnification of $\times 20(\mathbf{a}$ and $\mathbf{c})$ and $\times 100(\mathbf{b}$ and $\mathbf{d})$
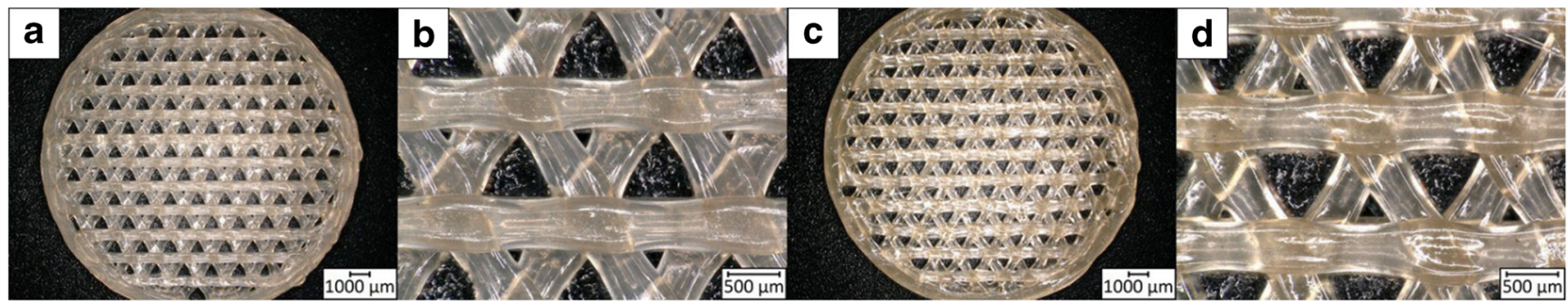

Fig. 10 Microscopic images of 80:20 PLLA:PLLATMC (a and b, sample S2) and 30:70 PLLA:PLLATMC (c and d, sample S6) scaffolds with 55\% porosity at the magnification of $\times 20(\mathbf{a}$ and $\mathbf{c})$ and $\times 100(\mathbf{b}$ and $\mathbf{d})$

result, the viscosity decrease. This effect is characteristic of the non-Newtonian fluids. Finally, at sufficiently high flow rates, the polymer chains are aligned in parallel. The flow is oriented, and consequently, the viscosity is constant again.

Measured viscosity was higher for $80: 20$ PLLA:PLLATMC blend which, given the similar chemical structure of the polymers, could be attributed to higher average molar mass in comparison with 30:70 PLLA:PLLATMC blend.

Additionally, the frequency sweep test for angular speeds between 1 and $600 \mathrm{rad} \mathrm{s}^{-1}$ was performed (Fig. 8). For this, the amplitude of the strain of $1 \%$ is constant, whereas the frequency varies. In the measuring conditions, the blends were characterized for the relatively small changes in the strain which are the typical conditions for the processing of polymers by FDM. The storage modulus, the loss modulus, and the complex viscosity were analyzed. The storage modulus corresponds to the elastic character of the material and to the retained energy during its deformation, whereas the loss modulus represents the viscous character and the dispersed energy.
Total resistance to the flow with the changes of the angular speeds is described by the complex viscosity. In the measuring conditions, both blends show viscoelastic behavior typical for the melted polymers with the loss modulus higher than the storage modulus. With the increasing angular velocities the complex viscosity decrease and both moduli increase. This is a result of the damages of the polymer chains arrangement with the changes in the stress.

\subsection{Sample preparation and characterization}

After the optimization of the 3D printing process parameters, they were applied for the preparation of the polymer scaffolds. Two series of the samples were prepared including 80:20 PLLA:PLLATMC scaffolds by FFF method (S1-S4) and 30:70 PLLA:PLLATMC scaffolds by FGF method (S5-S8) based of four different designed 3D models with the porosity of $65 \%$ (S1, S5), 55\% (S2, S6), 45\% (S3, S7) and 35\% (S4, S8). The height, the diameter and the mass of the samples were measured and based on them the porosity was calculated

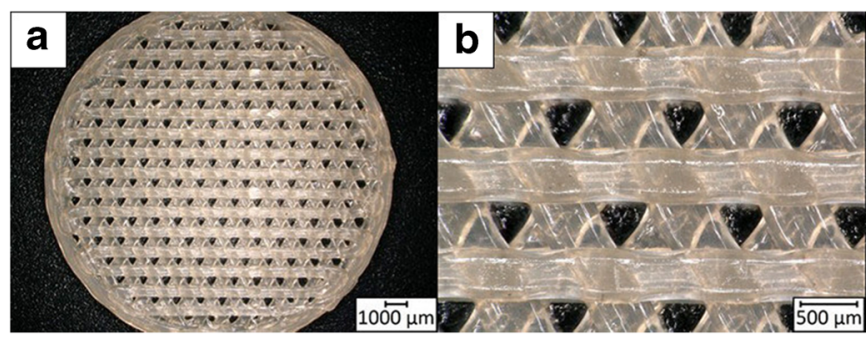

Fig. 11 Microscopic images of 80:20 PLLA:PLLATMC (a and b, sample S3) and 30:70 PLLA:PLLATMC (c and d, sample S7) scaffolds

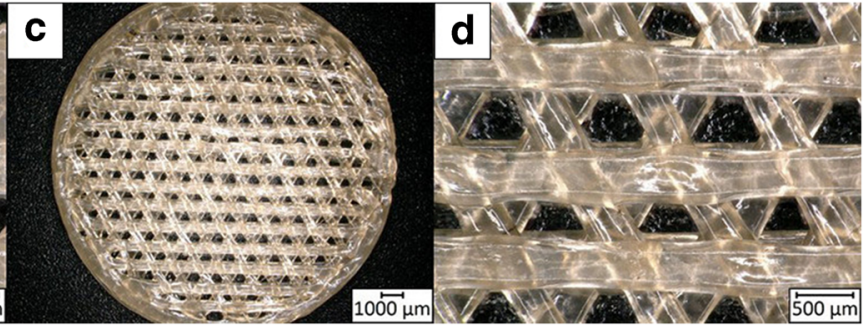

with $45 \%$ porosity at the magnification of $\times 20$ (a and $\mathbf{c})$ and $\times 100$ (b and d) 


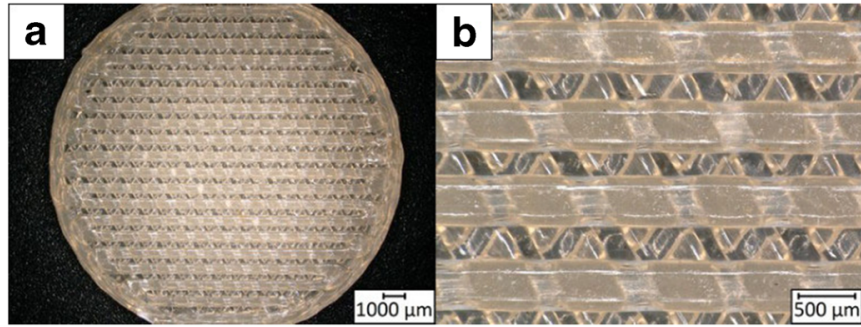

Fig. 12 Microscopic images of 80:20 PLLA:PLLATMC (a and b, sample S4) and 30:70 PLLA:PLLATMC (c and d, sample S8) scaffolds

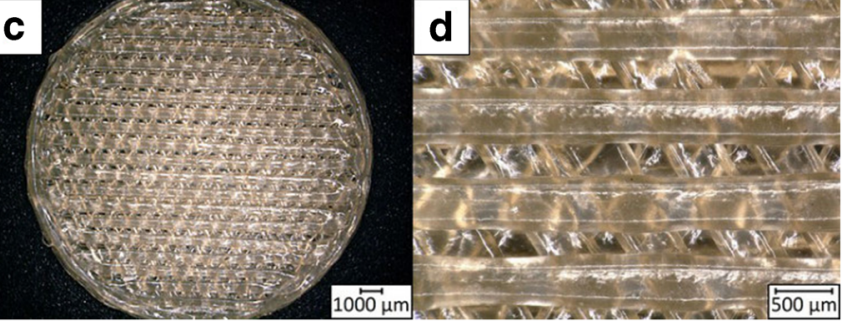

with $35 \%$ porosity at the magnification of $\times 20(\mathbf{a}$ and $\mathbf{c})$ and $\times 100$ (b and d)
(Table 3). The values of these parameters could be referred to the accuracy, whereas their standard deviations to the precision of the 3D printing method. Microscopic images of the scaffolds are presented in Figs. 9, 10, 11, and 12. It was observed that the geometry of the designed models was fully reproduced with the application of both FFF and FGF methods.

A few factors influencing the difference between obtained and designed geometry should be considered. The height of all scaffolds is reduced by $0.2 \mathrm{~mm}$ as a result of the difference between the first layer height of $0.3 \mathrm{~mm}$ and the initial nozzlebed distance of $0.1 \mathrm{~mm}$. The height and the diameter are lower than designed because of the shrinkage of the materials after the thermal processing which is higher for 30:70 PLLA:PLLATMC blend in comparison with 80:20 PLLA:PLLATMC blend. For the diameter, this effect is slightly diminished by the deformations related to the initial position of the nozzle. As a consequence, the obtained and designed porosity are more similar to each other for 80:20 PLLA:PLLATMC scaffolds in comparison with 30:70 PLLA:PLLATMC scaffolds. Furthermore, the difference in the geometry parameters of the specific sample is higher for 30:70 PLLA:PLLATMC blend. This could be explained as a consequence of the characteristic material deposition for FFF and FGF. The process is more stable and precise with the application of the filament in comparison with the granulate. Nevertheless, for both blends and both applied methods of their processing the geometry tolerance of the obtained scaffolds is appropriate for their potential application in tissue engineering. This also confirms a correct construction, optimization and application of the custom modification of $3 \mathrm{D}$ printer. It should be also noted that during the designing of $3 \mathrm{D}$ model it could be appropriately resized to compensate the changes of the dimensions related to the described effects. As a consequence, the quality of the prepared samples could be enhanced.

\section{Conclusions}

PLLA:PLLATMC blends could be processed using 3D printing by FDM and the low-cost RepRap 3D printer. However, depending on their mechanical properties a different approach has to be applied. The general procedure consists of two stages including the preparation of the material for $3 \mathrm{D}$ printing and the preparation of a specific product by $3 \mathrm{D}$ printing. The blends with sufficiently high mechanical properties like 80:20 PLLA:PLLATMC could be prepared in the form of filament and processed using the FFF method and the standard configuration of $3 \mathrm{D}$ printer. Otherwise, as for 30:70 PLLA:PLLATMC blend with low mechanical properties, the material has to be processed directly in the form of granulate. It requires the modification of the $3 \mathrm{D}$ printer construction to adapt to the FGF method. This was possible with the application of the RepRap 3D printer based on the open-source project, whereas in the case of many commercially available 3D printers, the modifications could not be introduced or they are highly expensive. 3D printing in comparison with many traditional methods of material processing, allows for the preparation of the products with a precisely defined and designed geometry including the shape, dimensions, porosity and pore size distribution. This could be used in case of the scaffolds for the therapy tailored to the needs of the specific patient. Detailed characterization of the samples shows that both FFF and FGF could be applied for the preparation of the scaffolds with high quality appropriate for their potential application in tissue engineering. FFF in comparison with FGF provides the higher precision and accuracy of the method, but the overall procedure is longer. In general, FGF is a more versatile method which could be applied to various thermoplastic polymers also with the additives when the brittleness of material makes the preparation of the filament difficult. However, for this method, the slightly worse quality of the product should be taken into consideration with regard to the specific requirements.

Open Access This article is licensed under a Creative Commons Attribution 4.0 International License, which permits use, sharing, adaptation, distribution and reproduction in any medium or format, as long as you give appropriate credit to the original author(s) and the source, provide a link to the Creative Commons licence, and indicate if changes were made. The images or other third party material in this article are included 
in the article's Creative Commons licence, unless indicated otherwise in a credit line to the material. If material is not included in the article's Creative Commons licence and your intended use is not permitted by statutory regulation or exceeds the permitted use, you will need to obtain permission directly from the copyright holder. To view a copy of this licence, visit http://creativecommons.org/licenses/by/4.0/.

\section{References}

1. Nair LS, Laurencin CT (2007) Biodegradable polymers as biomaterials. Prog Polym Sci 32(8-9):762-798. https://doi.org/10.1016/j. progpolymsci.2007.05.017

2. Goonoo N, Bhaw-Luximon A, Jhurry D (2015) Biodegradable polymer blends: miscibility, physicochemical properties and biological response of scaffolds. Polym Int 64(10):1289-1302. https://doi.org/10.1002/pi.4937

3. Imre B, Pukánszky B (2013) Compatibilization in bio-based and biodegradable polymer blends. Eur Polym J 49(6):1215-1233. https://doi.org/10.1016/j.eurpolymj.2013.01.019

4. Kim TG, Shin H, Lim DW (2012) Biomimetic scaffolds for tissue engineering. Adv Funct Mater 22(12):2446-2468. https://doi.org/ 10.1002/adfm.201103083

5. Chan BP, Leong KW (2008) Scaffolding in tissue engineering: general approaches and tissue-specific considerations. Eur Spine J 17(S4):S467-S479. https://doi.org/10.1007/s00586-008-0745-3

6. Liu CZ, Czernuszka JT (2007) Development of biodegradable scaffolds for tissue engineering: a perspective on emerging technology. Mater Sci Technol 23(4):379-391. https://doi.org/10.1179/ $174328407 X 177027$

7. O'Brien FJ (2011) Biomaterials \& scaffolds for tissue engineering. Mater Today 14(3):88-95. https://doi.org/10.1016/S1369-7021(11) 70058-X

8. Ngo TD, Kashani A, Imbalzano G, Nguyen KTQ, Hui D (2018) Additive manufacturing (3D printing): a review of materials, methods, applications and challenges. Compos Part B-Eng 143: 172-196. https://doi.org/10.1016/j.compositesb.2018.02.012

9. Tofail SAM, Koumoulos EP, Bandyopadhyay A, Bose S, O'Donoghue L, Charitidis C (2018) Additive manufacturing: scientific and technological challenges, market uptake and opportunities. Mater Today 21(1):22-37. https://doi.org/10.1016/j.mattod. 2017.07.001

10. Singh S, Ramakrishna S, Singh R (2017) Material issues in additive manufacturing: a review. J Manuf Process 25:185-200. https://doi. org/10.1016/j.jmapro.2016.11.006

11. Bowyer A (2014) 3D printing and humanity's first imperfect replicator. 3D. Print Addit Manuf 1(1):4-5. https://doi.org/10. 1089/3dp.2013.0003

12. Ligon SC, Liska R, Stampfl J, Gurr M, Mülhaupt R (2017) Polymers for $3 \mathrm{D}$ printing and customized additive manufacturing. Chem Rev 117(15):10212-10290. https://doi.org/10.1021/acs. chemrev.7b00074

13. Deckers J, Vleugels J, Kruth JP (2014) Additive manufacturing of ceramics: a review. J Ceram Sci Tech 5(4):245-260. https://doi.org/ 10.4416/JCST2014-00032

14. Herzog D, Seyda V, Wycisk E, Emmelmann C (2016) Additive manufacturing of metals. Acta Mater 117:371-392. https://doi. org/10.1016/j.actamat.2016.07.019

15. Tappa K, Jammalamadaka U (2018) Novel biomaterials used in medical 3D printing techniques. J Funct Biomater 9(1):e17. https://doi.org/10.3390/jfb9010017

16. Kyle S, Jessop ZM, Al-Sabah A, Whitaker IS (2017) 'Printability' of candidate biomaterials for extrusion based 3D printing: state-ofthe-art. Adv Healthc Mater 6(16):1700264. https://doi.org/10.1002/ adhm.201700264
17. Derakhshanfar S, Mbeleck R, Xu K, Zhang X, Zhong W, Xing M (2018) 3D bioprinting for biomedical devices and tissue engineering: a review of recent trends and advances. Bioact Mater 3(2):144 156. https://doi.org/10.1016/j.bioactmat.2017.11.008

18. An J, Teoh JEM, Suntornnond R, Chua CK (2015) Design and 3D printing of scaffolds and tissues. Engineering 1(2):261-268. https:// doi.org/10.15302/J-ENG-2015061

19. Ten Kate J, Smit G, Breedveld P (2017) 3D-printed upper limb prostheses: a review. Disabil Rehabil Assist Technol 12(3):300 314. https://doi.org/10.1080/17483107.2016.1253117

20. Trenfield SJ, Awad A, Goyanes A, Gaisford S, Basit AW (2018) 3D printing pharmaceuticals: drug development to frontline care. Trends Pharmacol Sci 39(5):440-451. https://doi.org/10.1016/j. tips.2018.02.006

21. Norman J, Madurawe RD, Moore CM, Khan MA, Khairuzzaman A (2017) A new chapter in pharmaceutical manufacturing: 3Dprinted drug products. Adv Drug Deliv Rev 108:39-50. https:// doi.org/10.1016/j.addr.2016.03.001

22. Langridge B, Momin S, Coumbe B, Woin E, Griffin M, Butler P (2018) Systematic review of the use of 3-dimensional printing in surgical teaching and assessment. J Surg Educ 75(1):209-221. https://doi.org/10.1016/j.jsurg.2017.06.033

23. Rankin TM, Giovinco NA, Cucher DJ, Watts G, Hurwitz B, Armstrong DG (2014) Three-dimensional printing surgical instruments: are we there yet? J Surg Res 189(2):193-197. https://doi. org/10.1016/j.jss.2014.02.020

24. Pretula J, Slomkowski S, Penczek S (2016) Polylactides - methods of synthesis and characterization. Adv Drug Deliv Rev 107:3-16. https://doi.org/10.1016/j.addr.2016.05.002

25. Farah S, Anderson DG, Langer R (2016) Physical and mechanical properties of PLA, and their functions in widespread applications a comprehensive review. Adv Drug Deliv Rev 107:367-392. https://doi.org/10.1016/j.addr.2016.06.012

26. Dubey SP, Thakur VK, Krishnaswamy S, Abhyankar HA, Marchante V, Brighton JL (2017) Progress in environmentalfriendly polymer nanocomposite material from PLA: synthesis, processing and applications. Vacuum 146:655-663. https://doi. org/10.1016/j.vacuum.2017.07.009

27. Robertson ML, Chang K, Gramlich WM, Hillmyer MA (2010) Toughening of Polylactide with polymerized soybean oil. Macromolecules 43(4):1807-1814. https://doi.org/10.1021/ ma9022795

28. Aydın RST, Akyol E, Hazer B (2017) Soybean oil based Polylactic acid membranes: synthesis and degradation characteristics. J Polym Environ 26(3):1262-1271. https://doi.org/10.1007/s10924-0171032-3

29. Castro-Aguirre E, Iñiguez-Franco F, Samsudin H, Fang X, Auras R (2016) Poly(lactic acid) - mass production, processing, industrial applications, and end of life. Adv Drug Deliv Rev 107:333-366. https://doi.org/10.1016/j.addr.2016.03.010

30. Poh PSP, Chhaya MP, Wunner FM, De-Juan-Pardo EM, Schilling AF, Schantz JT, van Griensven M, Hutmacher DW (2016) Polylactides in additive biomanufacturing. Adv Drug Deliv Rev 107:228-246. https://doi.org/10.1016/j.addr.2016.07.006

31. Davachi SM, Kaffashi B (2015) Polylactic acid in medicine. Polym Plast Technol 54(9):944-967. https://doi.org/10.1080/03602559. 2014.979507

32. Gregor A, Filová E, Novák M, Kronek J, Chlup H, Buzgo M, Blahnová V, Lukášová V, Bartoš M, Nečas A, Hošek J (2017) Designing of PLA scaffolds for bone tissue replacement fabricated by ordinary commercial 3D printer. J Biol Eng 11:31. https://doi. org/10.1186/s13036-017-0074-3

33. Esposito Corcione C, Gervaso F, Scalera F, Padmanabhan SK, Madaghiele M, Montagna F, Sannino A, Licciulli A, Maffezzoli A (2018) Highly loaded hydroxyapatite microsphere / PLA porous 
scaffolds obtained by fused deposition modeling. Ceram Int 45(2): 2803-2810. https://doi.org/10.1016/j.ceramint.2018.07.297

34. Ritz U, Gerke R, Götz H, Stein S, Rommens PM (2017) A new bone substitute developed from 3D-prints of Polylactide (PLA) loaded with collagen I: An in vitro study. Int J Mol Sci 18(12): e2569. https://doi.org/10.3390/ijms18122569

35. Torres-Giner S, Gimeno-Alcañiz JV, Ocio MJ, Lagaron JM (2011) Optimization of electrospun polylactide-based ultrathin fibers for osteoconductive bone scaffolds. J Appl Polym Sci 122(2):914925. https://doi.org/10.1002/app.34208

36. Bhaskar B, Owen R, Bahmaee H, Wally Z, Sreenivasa Rao P, Reilly GC (2018) Composite porous scaffold of PEG/PLA support improved bone matrix deposition in vitro compared to PLA-only scaffolds. J Biomed Mater Res A 106(5):1334-1340. https://doi.org/10. 1002/jbm.a.36336

37. Fukushima K (2016) Poly(trimethylene carbonate)-based polymers engineered for biodegradable functional biomaterials. Biomater Sci 4(1):9-24. https://doi.org/10.1039/c5bm00123d

38. Li H, Chang J, Qin Y, Wu Y, Yuan M, Zhang Y (2014) Poly(lactideco-trimethylene carbonate) and polylactide/polytrimethylene carbonate blown films. Int J Mol Sci 15(2):2608-2621. https://doi. org/10.3390/ijms 15022608

39. Song Y, Kamphuis MM, Zhang Z, Sterk LM, Vermes I, Poot AA, Feijen J, Grijpma DW (2010) Flexible and elastic porous poly(trimethylene carbonate) structures for use in vascular tissue engineering. Acta Biomater 6(4):1269-1277. https://doi.org/10. 1016/j.actbio.2009.10.002
40. Zhang Y, Liang RJ, Xu JJ, Shen LF, Gao JQ, Wang XP, Wang NN, Shou D, Hu Y (2017) Efficient induction of antimicrobial activity with vancomycin nanoparticle-loaded poly(trimethylene carbonate) localized drug delivery system. Int J Nanomedicine 12:1201-1214. https://doi.org/10.2147/IJN.S127715

41. Wach RA, Adamus A, Olejnik AK, Dierzawska J, Rosiak JM (2013) Nerve guidance channels based on PLLA-PTMC biomaterial. J Appl Polym Sci 127(3):2259-2268. https://doi.org/10.1002/ app.37932

42. Zhang S, Li H, Yuan M, Yuan M, Chen H (2017) Poly(lactic acid) blends with poly(Trimethylene carbonate) as biodegradable medical adhesive material. Int J Mol Sci 18(10):2041. https://doi.org/10. 3390/ijms18102041

43. Schüller-Ravoo S, Teixeira SM, Feijen J, Grijpma DW, Poot AA (2013) Flexible and elastic scaffolds for cartilage tissue engineering prepared by stereolithography using poly(trimethylene carbonate)based resins. Macromol Biosci 13(12):1711-1719. https://doi.org/ 10.1002/mabi.201300399

44. Marchewka J, Laska J (2018) Blends of poly(L-lactide) and poly(Llactide-co-trimethylene carbonate) as promising materials for bone and cartilage tissue engineering. Eng Biomater 21(145):8-15

Publisher's note Springer Nature remains neutral with regard to jurisdictional claims in published maps and institutional affiliations. 